\title{
Organcatalytic Transamination for the Synthesis of $\alpha$-Amino Acids
}

Peptide Chemistry

Key words

organocatalysis

transamination

keto esters

amino acids<smiles>[R]C(=O)C(=O)OCCCC</smiles>

(1.5 equiv)
1. catalyst $(5 \mathrm{~mol} \%)$

$4 \AA$ MS, mesitylene

$10^{\circ} \mathrm{C}$ to r.t., $16-72 \mathrm{~h}$

2. $1 \mathrm{~N} \mathrm{HCl}, \mathrm{THF}, 0{ }^{\circ} \mathrm{C}, 1 \mathrm{~h}$

3. $\mathrm{Et}_{3} \mathrm{~N}$ (2.0 equiv)

$\mathrm{BzCl}$ (2.0 equiv)

$0{ }^{\circ} \mathrm{C}, 30 \mathrm{~min}$

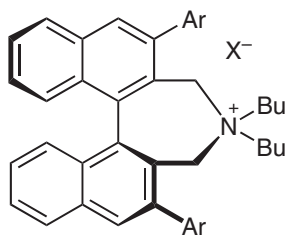

catalyst

$\mathrm{Ar}=3,4,5-\mathrm{F}_{3} \mathrm{C}_{6} \mathrm{H}_{2}$ $\mathrm{X}=2,4,6-\mathrm{Me}_{3} \mathrm{C}_{6} \mathrm{H}_{2} \mathrm{CO}_{2}$

\section{Selected examples:}<smiles>CCCCC(=O)C(CCCc1ccccc1)OC</smiles>

$65 \%$ yield, $88 \%$ ee<smiles>C=CCCC(N)C(=O)OC</smiles>

$58 \%$ yield, $86 \%$ ee<smiles>C=C(C)CCCC(=C)CCC(N)C(=O)OC</smiles>

$48 \%$ yield, $86 \%$ ee

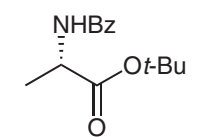

$72 \%$ yield, $80 \%$ ee<smiles>[2H]C(=O)C(=O)OCc1ccc([N+](=O)[O-])cc1</smiles>

(1.5 equiv)

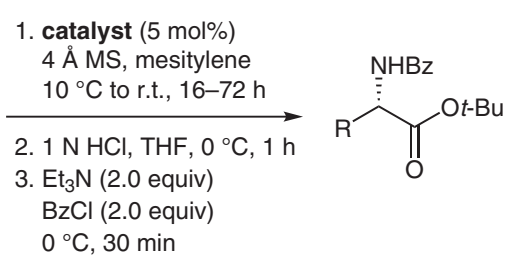

$0{ }^{\circ} \mathrm{C}, 30 \mathrm{~min}$

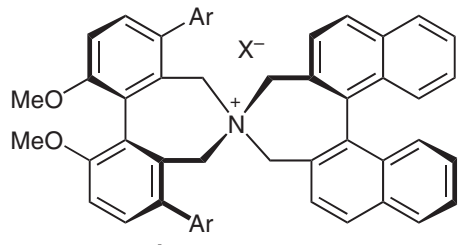

catalyst

$\mathrm{Ar}=3,4,5-\mathrm{F}_{3} \mathrm{C}_{6} \mathrm{H}_{2}$

$\mathrm{X}=2,4,6-\mathrm{Me}_{3} \mathrm{C}_{6} \mathrm{H}_{2} \mathrm{CO}_{2}$

Selected examples:<smiles>CCCCC(=O)OC(=O)[C@H](N)CCC1=CCCCC1</smiles>

$40 \%$ yield, $86 \%$ ee<smiles>CCCCC(=O)OC(=O)C(N)CCC(=O)OCC</smiles>

$40 \%$ yield, $80 \%$ ee<smiles>CCCCC(=O)OC(=O)[C@H](N)CCCOCc1ccccc1</smiles>

$64 \%$ yield, $72 \%$ ee<smiles>CCCCCCCCCCCOC(=O)C(N)CCCCC</smiles>

$44 \%$ yield, $86 \%$ ee
Significance: Asymmetric metal-free transformation is one of the most useful and environmentally friendly techniques for the synthesis of chiral organic compounds. The authors describe a powerful method for the synthesis of $\alpha$-amino acid derivatives catalyzed by novel chiral phase-transfer catalysts.
Comment: This organocatalytic enantioselective transformation of $\alpha$-keto esters with benzyl amines smoothly provides the corresponding $\alpha$-amino acid derivatives in moderate yields with good enantioselectivities. 